\section{WHO's reply to 'Cholera in the time of War: implications of weak surveillance in Syria for the WHO's preparedness - a comparison of two monitoring systems}

\section{Dear Editor,}

Early detection of outbreaks is a major challenge in most countries, and more specifically when they endure a conflict. In the protracted Syrian crisis, WHO is currently supporting two surveillance systems ${ }^{1}$ which were recently subject to an evaluation by Sparrow et $a l^{2}$

The early warning and response system (EWARS), established in September 2012 by the Ministry of Health and based in Damascus, covers mainly governmentcontrolled areas of the country. The early warning and response network (EWARN), set up in June 2013 by the Syrian National Coalition, is headquartered in Gaziantep, Turkey, and covers mainly oppositioncontrolled areas. These two early warning mechanisms are currently supporting Syria's routine public health surveillance system.

During its short lifetime, EWARS has expanded to cover more than 1100 health facilities situated in all 14 governorates of the country. EWARS has access to diagnostic laboratories and has confirmed outbreaks of polio, hepatitis, typhoid, seasonal influenza (H1N1 pdm09) and cutaneous leishmaniasis. Some of these outbreaks were detected in opposition-controlled areas. EWARN gathers data from more than 500 sites in 12 governorates with 3 diagnostic laboratories established with the support provided by WHO.

In their study, Sparrow et al compared the performance of EWARS and EWARN in reporting waterborne diseases (with a focus on cholera) based on two main indicators-the timeliness and completeness of reports. They found that EWARS reports were subject to longer delays than EWARN reports (ie, they were less timely, although there was considerable variation and overlap in reporting delays). They also found that EWARS reports were less complete.

These findings are instructive, but they raise questions that do not yet have clear answers. For example, did EWARS perform relatively poorly in this evaluation as a direct result of the conflict (EWARS and EWARN are operating under different conditions), or because there was external influence on reporting by the Syrian government, or for some other reason? Sparrow et al emphasise the risk of government interference, but there is no evidence yet to determine which explanation is correct.

Sparrow et al have also misinterpreted the value of the two surveillance systems and the role and independence of WHO. Owing to their different geographical areas of coverage, the two surveillance systems are complementary, together providing a more complete national picture of infectious disease outbreaks. WHO does not rely solely on EWARS, and does not work solely in government-controlled areas. Rather, both systems have been established with technical support and supervision from $\mathrm{WHO}$, and the data provided by these systems are analysed together on a weekly basis.

EWARS and EWARN each face significant operating challenges. Both systems need to be evaluated and improved against a range of benchmarks-going beyond timeliness and completeness of reporting to include, for example, the timeliness of response, the detection of alerts, usefulness of the system, simplicity, specificity, sensitivity and other aspects of the system. ${ }^{3}$ Further evaluations of this kind from Syria will add to the body of knowledge about early warning systems already obtained from Iraq, Pakistan, Sudan and South Sudan, among other countries. ${ }^{5-8}$

As the Syrian tragedy continues to unfold, it is important to recognise that both EWARN and EWARS are needed to maximise surveillance coverage of the Syrian population. Complementary data of the highest quality from the two systems are vital in protecting the health of all the inhabitants of Syria.

\section{Ghada Muhjazi, Mamunur Malik, Peter Mala, Pierre Nabeth, Christopher Dye}

World Health Organization Country Office for Syrian Arab Republic, Damascus, Syrian Arab Republic

\section{Correspondence to Dr Ghada Muhjazi; muhjazig@who.int}

Competing interests None declared.

Provenance and peer review Not commissioned; internally peer reviewed.

Open Access This is an Open Access article distributed in accordance with the Creative Commons Attribution Non Commercial (CC BY-NC 4.0) license, which permits others to distribute, remix, adapt, build upon this work noncommercially, and license their derivative works on different terms, provided the original work is properly cited and the use is non-commercial. See: http:// creativecommons.org/licenses/by-nc/4.0/

To cite: Muhjazi G, Malik M, Mala P, et al. WHO's reply to ‘Cholera in the time of War: implications of weak surveillance in Syria for the WHO's preparedness -a comparison of two monitoring systems. BMJ Global Health 2017;2: e000258. doi:10.1136/bmjgh-2016-000258

Received 1 December 2016 Accepted 10 January 2017

BMJ Glob Health 2017;2:e000258. doi:10.1136/bmjgh-2016-000258

\section{REFERENCES}

1. Mala P, Ghada M, Wasan A, et al. Establishment of EWARN system for the Syrian crisis: experiences and challenges. Int $J$ Infect Dis 2014;21:280.

2. Sparrow A, Almilaji K, Tajaldin B, et al. Cholera in the time of war: implications of weak surveillance in Syria for the WHO's preparedness-a comparison of two monitoring systems. BMJ Glob Health 2016;1:e000029.

3. WHO. Communicable diseases surveillance and response system Guide to monitoring and evaluation. Geneva, 2006.

4. CDC. Guidelines for Evaluating Surveillance System. http://www.cdc. $\mathrm{gov} / \mathrm{mmwr} / \mathrm{preview} / \mathrm{mmwrhtml} / 00001769$.htm.

5. Centers for Disease Control and Prevention (CDC). Early warning disease surveillance after a flood emergency-Pakistan, 2010. MMWR Morb Mortal Wkly Rep 2012;61:1002-7. 
6. Pinto A, Saeed M, Sakka $H$, et al. Setting up an early warning system for epidemic-prone diseases in Darfur: a participative approach. Disasters 2005;29:310-22.

7. Rahim M, Kazi B, Bile K, et al. The impact of the disease early warning system in responding to natural disasters and conflict crises in Pakistan. East Mediterr Health 2010;16(Suppl):S114-21.
8. Ahmed K, Altaf MD, Dureab F. Electronic infectious disease surveillance system during humanitarian crises in Yemen. Online J Public Health Inform 2014;6:e134. 